\title{
An iterative process of global quality improvement: the International Standards for a Safe Practice of Anesthesia 2010
}

\author{
Alan F. Merry, FANZCA $\cdot$ Jeffrey B. Cooper, PhD • \\ Olaitan Soyannwo, MMed · Iain H. Wilson, FRCA • \\ John H. Eichhorn, MD
}

Received: 9 July 2010/Accepted: 16 August 2010/Published online: 21 September 2010

(C) The Author(s) 2010

\begin{abstract}
Purpose To enhance patient safety through contemporaneous and comprehensive standards for a safe practice of anesthesia that augment, enhance, and support similar standards already published by various countries and that provide a resource for countries that have yet to formulate such standards.
\end{abstract}

A.F. Merry is Chair of the Quality and Safety Committee and I.H. Wilson is Chair of the Publications Committee of the World Federation of Societies of Anaesthesiologists.

\section{A. F. Merry, FANZCA ( $\square)$}

Department of Anaesthesiology, University of Auckland and Department of Anaesthesia, Auckland City Hospital, Private Bag 92019, Auckland 1142, New Zealand

e-mail: a.merry@auckland.ac.nz

\section{J. B. Cooper, PhD}

Department of Anesthesia, Critical Care and Pain Medicine,

Massachusetts General Hospital, Boston, MA, USA

O. Soyannwo, MMed

Department of Anaesthesia, University of Ibadan College

of Medicine/University College Hospital, Ibadan, Nigeria

I. H. Wilson, FRCA

Royal Devon and Exeter NHS Foundation Trust, Exeter, Devon, UK

\section{J. H. Eichhorn, MD}

Department of Anesthesiology, University of Kentucky

College of Medicine and Medical Center, Lexington, KY, USA

A. F. Merry, FANZCA · J. B. Cooper, PhD .

O. Soyannwo, MMed · I. H. Wilson, FRCA ·

J. H. Eichhorn, MD

Safe Anesthesia Working Group of the World Health

Organization's Safe Surgery Saves Lives Global Challenge,

Exeter, UK
Standards development The Safe Anesthesia Working Group of the World Health Organization's "Safe Surgery Saves Lives" global initiative updated the 1992 International Standards for the Safe Practice of Anaesthesia (Standards) through an iterative process of literature review, consultation, debate, drafting, and refinement. These Standards address, in detail, the organization, support, practices, and infrastructure for anesthesia care. The Standards are grounded in the fundamental principle of safety in anesthesia, i.e., the continuous presence of an appropriately trained, vigilant anesthesia professional. In effect, the use of pulse oximetry during anesthesia is now considered mandatory, with acknowledgement that compromise may be unavoidable in emergencies. At the World Congress of Anaesthesiologists in 2008, drafts were presented for comment, further refinements were made, and the Revised Standards were adopted by the World Federation of Societies of Anaesthesiologists (WFSA). These Revised Standards were posted on the WFSA website for further feedback, and minor revisions followed. The International Standards for a Safe Practice of Anesthesia 2010 were endorsed by the Executive Committee of the WFSA in March 2010. Ongoing periodic revision is planned.

Conclusion While they are universally applicable, the 2010 Standards primarily target lesser-resourced areas. They are designed particularly for regions that have yet to formulate or adopt their own standards so as to promote optimum patient outcomes in every anesthetizing location in the world.

\section{Résumé}

Objectif Améliorer la sécurité des patients grâce à des normes contemporaines et détaillées pour une pratique 
sécuritaire de l'anesthésie qui augmentent, améliorent et appuient les normes semblables déjà publiées par divers pays et procurent une ressource aux pays qui doivent encore elaborer de telles normes.

Élaboration des normes L'initiative mondiale "Une chirurgie plus sûre pour sauver des vies "du Groupe de travail pour la sécurité en anesthésie de l'Organisation mondiale de la Santé a mis à jour les Normes internationales pour une pratique sécuritaire de l'anesthésie de 1992 (1992 International Standards for the Safe Practice of Anaesthesia) par un processus itératif de revue de la littérature, de consultation, de débat, de réécriture et de perfectionnement. Ces Normes abordent de façon détaillée les questions d'organisation, de soutien, de pratique et d'infrastructure liées aux soins en anesthésie. Elles se fondent sur le principe fondamental de la sécurité en anesthésie, soit la présence ininterrompue d'un professionnel de l'anesthésie vigilant et adéquatement formé. Dans les faits, l'utilisation de l'oxymétrie de pouls pendant l'anesthésie est désormais considérée comme obligatoire, tout en reconnaissant que, dans les cas d'urgence, un compromis peut être inévitable. Lors du Congrès mondial des anesthésiologistes de 2008, plusieurs avant-projets ont été présentés afin d'être discutés, certains points ont été perfectionnés, et les Normes révisées ont été adoptées par la Fédération mondiale des sociétés d'anesthésiologistes (FMSA). Ces Normes révisées ont été publiées sur le site Internet de la FMSA avec un appel aux commentaires, et quelques révisions mineures y ont encore été apportées. Les Normes internationales pour une pratique sécuritaire de l'anesthésie de 2010 ont été avalisées par le Conseil de direction de la FMSA en mars 2010. Un processus continu de révision périodique est prévu.

Conclusion Tout en étant applicables universellement, les Normes de 2010 s'adressent principalement aux régions du monde disposant de ressources limitées. Elles sont particulièrement conçues à l'intention des régions qui doivent encore formuler ou adopter leurs propres normes afin de favoriser des devenirs de patients optimaux partout où l'anesthésie est pratiquée dans le monde.

\section{Introduction}

Anesthesiology as a profession was the pioneer-and persists as the leader-in improving quality of care and, hence, patient outcome through the development and application of published standards of practice, guidelines, and protocols. As a precursor to contributing the anesthesia care component to the Second Global Challenge of the World Health Organization (WHO), "Safe Surgery Saves Lives", 1 a WHO working group updated the 1992
International Standards for the Safe Practice of Anaesthesia of the World Federation of Societies of Anaesthesiologists (WFSA). ${ }^{2}$ That update is presented in the Journal owing to a cooperative developmental process that can serve both as a quality improvement template within and beyond anesthesiology and as a resource for all anesthesia professionals in all types of anesthetizing settings throughout the world.

The importance of surgery to worldwide public health has become increasingly apparent in recent years. ${ }^{3}$ That importance has increased with the advent of an epidemiological shift; longstanding leading causes of the global burden of disease, such as malnutrition and infectious diseases are still important, but conditions amenable to surgical treatment, such as childbirth complications, cancer, and trauma (notably road traffic accidents) have become relatively more prominent. This trend is likely to increase. Over 230 million surgical procedures are carried out annually around the world, which is twice the number of births. Surgical procedures are unevenly distributed, and the standard of care associated with them is inconsistent. Safe surgery is dependent on safe anesthesia, and variation in the standard of anesthesia care is particularly marked. ${ }^{4,5}$ In most highincome countries, anesthesia has become extremely safe. Rates of mortality attributable to anesthesia are typically less than 1 in 50,000 procedures. ${ }^{6}$ Unfortunately, the rate is often at least ten times higher in other parts of the world ${ }^{7-9}$

Improvements in anesthesia safety in high-income countries can be attributed to a number of contributing factors. One obvious factor in many such countries has been the adoption of standards for intraoperative "safety monitoring" ${ }^{10}$ based on the original precedent-setting Harvard Standards for Minimal Monitoring ${ }^{11}$ from the mid $1980 \mathrm{~s}$. Improved monitoring provides early warning of adverse events or developments and thus time for remediation and prevention of patient harm. Monitoring standards are useful, not only in establishing best practices but also in adding authoritative support to political arguments over the proportion of limited healthcare resources that ought to be directed towards anesthesia. To retain their value and authority, standards should be revised on a regular basis.

At the beginning of the $1990 \mathrm{~s}$, an independent group of anesthesiologists (The International Taskforce on Anaesthesia Safety) set itself a mission: "To enhance the safety of anaesthesia by promotion of international standards for anaesthesia practice." The intent was not to supersede safety standards already published by various countries; rather, the goal was to augment, enhance, and support published standards while providing a model and resource for countries that had yet to formulate or adopt such standards. The resulting document included two sections, "General Standards" and "Perianesthetic Care and Monitoring Standards". The former section covered, in detail, 
certain essential characteristics, such as professional status, organization, and training; it also dealt with general matters, such as records, peer review, personnel requirements, and appropriate workloads. The latter section was notable for its novel formulation of different levels of resource availability, which acknowledged the wide variability of available medical resources around the world. These Standards were endorsed and adopted as the world standards by the WFSA at its World Congress of Anaesthesiologists at The Hague in $19922^{2}$

In 2002, the World Health Assembly adopted a resolution urging countries to strengthen the safety of healthcare and monitoring systems, and in 2004, the World Alliance for Patient Safety was established within WHO. A number of developments have followed, including the Global Initiative for Emergency and Essential Surgical Care in 2005 and two Global Patient Safety Challenges. The second of these challenges, "Safe Surgery Saves Lives", which was initiated in 2007, addressed safety in surgical care. ${ }^{1}$ This program is perhaps best known for the WHO Surgical Safety Checklist that is the widely publicized leading component of the comprehensive parent document, the WHO Guidelines for Safe Surgery. ${ }^{12}$

Four of the WHO "Safe Surgery Saves Lives" working groups were given the task of addressing ten objectives. As members of the Safe Anesthesia Working Group, the authors of this paper were asked to focus on those objectives related to safer anesthesia. In effect, we realized that what was required were comprehensive guidelines for safe anesthesia. We further recognized the value of the foundational work undertaken by the International Taskforce nearly 20 years earlier, and we appreciated the advantages of building on this work rather than simply trying to repeat it. It became clear that there was still a substantial need for such standards and that revision of the 1992 International Standards was overdue.

Therefore, we have revised and updated the International Standards for a Safe Practice of Anaesthesia (Standards) in parallel with contributing to the WHO Guidelines for Safe Surgery, and the revised version is published in this issue.

\section{Standards development}

The formulation of the 1992 Standards has been fully described. ${ }^{13}$ In brief, following inception by Drs. J.H. Eichhorn and J.S. Gravenstein and the securing of funding, membership on the International Taskforce on Anesthesia Safety was offered, by invitation, to a group of ten independent individuals with strong credentials in their national anesthesia patient safety movements who were from countries that had or were formulating anesthesia safety standards. This group met initially in Amsterdam in 1989. The members collected copies of all of the available anesthesia standards documents from around the world. Extensive debate on the scope and content of the Standards (taking into account the applicability of the Standards to a wide range of settings and resources) was carried on via correspondence and facsimile transmission and at twice yearly face-to-face meetings. Consultation occurred with senior anesthesia professionals from a wide variety of countries. The Standards were written on the basis of all of this input through a long iterative process of drafting and refinement. At The Hague in June 1992, they were presented to the Tenth World Congress of Anaesthesiologists in two plenary sessions dedicated to this purpose. At this Congress, the General Assembly of the WFSA adopted the Standards document as their official world standards and commended it to its member societies. The document and a series of supporting background articles were published subsequently in the European Journal of Anaesthesiology. ${ }^{14}$

On the basis of their credentials in relation to patient safety, the authors of this current paper were invited to the Safe Surgery Saves Lives International Consultation led by Dr. Atul Gawande at the WHO headquarters in Geneva in January 2007. The purpose of this meeting was to address the following two questions:

1) What are the minimum standards of surgical care that can be applied universally across countries of different economic standards and different healthcare settings that will have the greatest impact on improving the safety of surgical care?

2) What measurement systems can be implemented to monitor the progress and improvement of surgical safety resulting from these standards?

Discussion of these objectives occurred through a series of moderated panels, each focused on a particular element of the wider issue. At the end of this consultation meeting, four working groups were established, including the Safe Anesthesia Working Group (the Group).

Subsequent work was done by the individual members of the Group, communicating through email, telephone, and face-to-face meetings as opportunities arose. Three further formal face-to-face meetings of the wider group took place. In relation to the Standards, evidence on individual aspects of anesthesia care (notably pulse oximetry) was sought from a number of sources with the aim of identifying all relevant publications and data sources. We carried out systematic searches of the literature using Medline and PubMed; we checked the references of retrieved publications, and we used personal communication. We consulted with colleagues in our own and other countries, particularly seeking to obtain the views of those 
from areas not represented within the Group. As part of the overall process of developing the Checklist, key issues were debated extensively with a broader group of international experts that convened in Geneva at WHO headquarters in January 2008. The Revised Standards were drafted iteratively on the basis of the information that emerged from this process. The overall structure of the original 1992 Standards was retained, but the terminology was aligned with that of the WHO.

The WHO Guidelines for Safe Surgery have been validated through the pilot study of the Checklist. ${ }^{15}$ The recommendations in the Revised Standards are aligned with those in the Guidelines, although the exact phrasing differs. Importantly, while both documents are intended primarily as stimuli, models, and resources for quality improvement efforts in resource-constrained areas of the world, the principles and practices outlined are universally applicable and relevant in every surgical and anesthetizing setting anywhere, even the most technologically advanced ultra-sophisticated operating theatres in teaching hospitals of major world capitals.

These Revised Standards were presented and discussed at a plenary session of the World Congress of Anaesthesiologists in Cape Town in March 2008 and at two General Assemblies of the WFSA held at this Congress. Further refinements were made on the basis of feedback from these presentations, and a final revision was endorsed by the WFSA at its third General Assembly held in Cape Town on March 7, 2008.

The 2008 International Standards for a Safe Practice of Anaesthesia were posted on the Website of the WFSA. Further feedback has been received, and minor revisions were made. This further revised edition was presented to the Executive Committee of the WFSA in London in March 2010. The Executive Committee endorsed the edition and further accepted the necessity of an ongoing process of revision. It was agreed that the 2010 Revised Standards - with an accompanying description of their development-should be submitted for open access publication in a peer-reviewed journal with the view to facilitating the dissemination of the standards and promoting feedback though the journal's correspondence columns. It was further agreed that the endorsement (or otherwise) of future revisions should be made by the Executive Committee of WFSA. Since this Committee meets every two years, the next clear opportunity for revision of the Standards will be in 2012 at the World Congress of Anaesthesiologists in Buenos Aeries.

The International Standards for a Safe Practice of Anesthesia 2010 are divided into two sections, "General Standards" and "Perianesthetic Care and Monitoring Standards". In keeping with the particularly effective approach of the original standards, there are three graduated levels of practice recommendations, and these levels are aligned with three increasing levels of applicable infrastructure.

\section{Interpretation}

The 2010 Standards specify the practices and resources required as a minimum for the provision of anesthesia for an elective surgical procedure, and they explicitly acknowledge that compromise may be unavoidable in an emergency. They are grounded in the most fundamental principle of safety in anesthesia, i.e., the continuous presence of a vigilant anesthesia professional during anesthesia. This requirement may seem obvious to many in 2010 , but it was actually controversial when first introduced, and we have anecdotal observational evidence that the point still needs to be made. The 2010 Standards specify further that providers of anesthesia care should be appropriately trained and accredited. The WFSA views anesthesia as a medical practice but recognizes the reality that many anesthetics are provided by non-medical personnel (even in a number of high-income countries). Nonetheless, leadership, training, direction, and supervision by medical personnel are specified. This parallels the situation found in other specialties, such as radiology, pathology, and cardiology. For example, a trained technician may well be capable of obtaining radiographs or echocardiographic views, and even of interpreting these. Yet, the need for broadly based medical expertise to direct radiological services or to deal with the implications of echocardiographic findings to patient management is not controversial. In the same way, there are clearly many aspects of anesthesia care that can be provided safely by appropriately trained non-medical health personnel. However, the prescription of optimum anesthesia, the complexity and variety of patients' comorbidities, the management of crises (which can develop quickly and without warning), and the broader issues of the appropriateness of the overall surgical management of certain patients are all areas for which formal medical training is required. Working together as a team, politically and perioperatively, allows the optimum configuration to be developed by medical and non-medical providers in different hospitals.

Perhaps the most controversial aspect of the 2010 Standards is the elevation of pulse oximetry to the highest level of recommendation, making its use, in effect, a mandatory standard of care. This was a carefully considered decision, and the rationale for it has been explained previously. ${ }^{16}$ We have surveyed WFSA member societies, and we have yet to find a national society that has minimal standards for anesthesia that does not specify pulse oximetry as mandatory. However, there is a discrepancy 
between the standards of some national societies and the actual availability of pulse oximetry in their regions. The extent of this substantial "oximetry gap" has recently been estimated. ${ }^{17}$ After proof of the concept through pilot studies in four countries, ${ }^{18}$ a major project is underway to address this gap through the provision of a package that includes appropriately designed and relatively affordable oximeters and training for the personnel who will use the oximeters. In combination with this initiative, the 2010 Standards have the potential to stimulate a major step forward in the care of anesthetized patients in some of the least-resourced areas of the world.

There are obvious limitations in the process that was used to develop the 2010 Standards. Every effort was made to ensure that relevant evidence from the literature was identified. However, elements of the 2010 Standards are a reflection of expert consensus based on many years of collective clinical experience. There have been epidemiologic trends and, from the USA, observed decreases in the frequency and severity of malpractice lawsuits for anesthesia injury accidents, which suggests improved anesthesia outcome associated with observing safety standards. ${ }^{19}$ There are no randomized trials to support the contention that the continuous presence of a trained anesthesiologist is essential for safe anesthesia. Neither is there a need for such trials. ${ }^{20,21}$ There is limited evidence from randomized trials regarding the value of pulse oximetry in anesthesia, but while this evidence is inconclusive, there can be few aspects of medical practice about which expert consensus is more unified or more supported in actual clinical practice. ${ }^{22}$ There has been little if any criticism of the original 1992 Standards since their publication, and the publication of the 2010 Standards in a widely accessible indexed medical journal provides a clear mechanism for discussion of any points thought to be contentious.

\section{Conclusions}

The International Standards for a Safe Practice of Anesthesia 2010 have been developed through an extensive process of literature review and international consultation. They were built on the thorough and carefully planned groundwork by the $1990 \mathrm{~s}$ Task Force. The first edition of the Standards stood the test of over 15 years of use. The establishment of a process for revision and iterative endorsement is an important step forward to ensure the ongoing relevance of the Standards to anesthesia practice throughout the world and to maintain a continuous stimulus for quality improvement in anesthesia care. While they are universally applicable, these Standards primarily target lesser-resourced areas. They are designed particularly for regions that have yet to formulate or adopt their own standards so as to promote optimum patient outcomes in every anesthetizing location in the world.

Acknowledgements The authors thank Dr. M.N. Cherian for her invaluable contribution, as a member of the Safe Anesthesia Working Group, to the development of the Standards. The authors gratefully acknowledge the support and input of Dr. Atul Gawande and the other leaders of the WHO "Safe Surgery Saves Lives" program (notably Drs. G. Dziekan, W.R. Berry, T.G. Weiser, and A.B. Haynes), as well as the constant encouragement and facilitation by the WFSA leadership, particularly current WFSA President, Dr. Angela Enright.

Conflicts of interest A. F. Merry has financial interests in Safer Sleep LLC.

Open Access This article is distributed under the terms of the Creative Commons Attribution Noncommercial License which permits any noncommercial use, distribution, and reproduction in any medium, provided the original author(s) and source are credited.

\section{References}

1. World Alliance for Patient Safety (2007) Global patient safety challenge 2007-08: Safe Surgery Saves Lives. Geneva: WHO, Available from URL: http://www.who.int/patientsafety/challenge/ safe.surgery/en/ (accessed June 2010).

2. International Taskforce on Anaesthesia Safety. International standards for a safe practice of anaesthesia. Eur J Anaesthesiol 1993; 10(7): 12-5.

3. Weiser TG, Regenbogen SE, Thompson KD, et al. An estimation of the global volume of surgery: a modelling strategy based on available data. Lancet 2008; 372: 139-44.

4. Walker IA, Wilson IH. Anaesthesia in developing countries-a risk for patients. Lancet 2008; 371: 968-9.

5. Walker I, Wilson I, Bogod D. Anaesthesia in developing countries. Anaesthesia 2007; 62(1): 2-3.

6. Gibbs N, Rodoreda P. Anaesthetic mortality rates in Western Australia 1980-2002. Anaesth Intensive Care 2005; 33: 616-22.

7. McKenzie AG. Mortality associated with anaesthesia at Zimbabwean teaching hospitals. South African Medical Journal 1996; 86: 338-42.

8. Hansen D, Gausi SC, Merikebu M. Anaesthesia in Malawi: complications and deaths. Trop Doct 2000; 30: 146-9.

9. Ouro-Bang'na Maman AF, Tomta K, Ahouangbevi S, Chobli M. Deaths associated with anaesthesia in Togo, West Africa. Trop Doct 2005; 35: 220-2.

10. Eichhorn JH. Prevention of intraoperative anesthesia accidents and related severe injury through safety monitoring. Anesthesiology 1989; 70: 572-7.

11. Eichhorn JH, Cooper JB, Cullen DJ, Maier WR, Philip JH, Seeman $R G$. Standards for patient monitoring during anesthesia at Harvard Medical School. JAMA 1986; 256: 1017-20.

12. WHO Guidelines for Safe Surgery (2009) Safe Surgery Saves Lives. WHO Press: World Health Organization, Geneva, Available from URL: http://whqlibdoc.who.int/publications/2009/978 9241598552_eng.pdf (accessed June 2010).

13. Eichhorn $J H$. The standards formulation process. Eur J Anaesthesiol Suppl 1993; 7: 9-11.

14. International standards for a safe practice of anaesthesia. (1993) Eur J Anaesthesiol 10(7):1-42.

15. Haynes $A B$, Weiser $T G$, Berry $W R$, et al. A surgical safety checklist to reduce morbidity and mortality in a global population. N Engl J Med 2009; 360: 491-9. 
16. Enright A, Merry A. The WFSA and patient safety in the perioperative setting. Can J Anesth 2009; 56: 8-13.

17. Funk LM, Weiser TG, Berry WR, et al. Global operating theatre distribution and pulse oximetry supply: an estimation from reported data. Lancet 2010; DOI: 10.1016/S0140-6736(08)61 345-8.

18. Walker IA, Merry AF, Wilson IH, et al. Global oximetry: an international anaesthesia quality improvement project. Anaesthesia 2009; 64: 1051-60.

19. Eichhorn JH (1992) Influence of practice standards on anesthesia outcome. In: Desmonts JM (Ed.) Outcome After Anesthesia and
Surgery. Bailliere's Clinical Anaesthesiology, International Practice and Research 10:663-90.

20. Merry AF, Davies JM, Maltby JR. Qualitative research in health care. Br J Anaesth 2000; 84: 552-5.

21. Smith GC, Pell JP. Parachute use to prevent death and major trauma related to gravitational challenge: systematic review of randomised controlled trials. BMJ 2003; 327: 1459-61.

22. Merry AF, Eichhorn JH, Wilson IH. Extending the WHO 'Safe Surgery Saves Lives' project through Global Oximetry. Anaesthesia 2009; 64: 1045-8. 